\title{
Effects of Compound Rust Inhibitor on the Performance of Concrete with a Large Amount of Mineral Admixtures
}

\author{
Song Lu, Jun Li, Zaie Luo*, Xiaojun Yang, Qingrui Gu, Xiangyu Liu \\ China Construction Third Engineering Bureau Group Co., Ltd, Beijing 100097, China
}

Corresponding Author Email: zjsjbj@ cscec.com

https://doi.org/10.18280/rcma.300208

Received: 17 November 2019

Accepted: 21 January 2020

\section{Keywords:}

concrete, mineral admixture, compound rust inhibitor, chloride penetration resistance, carbonation resistance, steel corrosion rate

\begin{abstract}
The corrosion of rebars in concrete is a major cause of the falling bearing capacity of concrete structures. The durability of concrete could be effectively enhanced by adding mineral admixtures. Many studies have shown that rust inhibitors can effectively prevent rebar corrosion. Taking commonly used slag, fly ash, and silica fume as mineral admixtures, this paper explores how an alcohol-amine compound rust inhibitor affects the compressive strength, chloride penetration resistance, carbonation resistance, and rebar corrosion resistance of concrete with a large amount of mineral admixtures. The research results show that the addition of rust inhibitor hinders the early hydration of cementitious materials in concrete; the chloride diffusivity and carbonation depth of concrete were minimized, when the ratio of $\mathrm{N}, \mathrm{N}$-dimethylethanolamine (DMEA) to sodium monofluorophosphate (MFP) in the compound rust inhibitor stands at 15:1; the addition of rust inhibitor clearly suppressed the corrosion loss of the rebars in concrete, resulting in a low rebar corrosion rate. The research results provide experimental evidence for reducing rebar corrosion in reinforced concrete.
\end{abstract}

\section{INTRODUCTION}

Reinforced concrete is the most widely used structural form in the world. It has been adopted in various types of infrastructures [1]. In actual environment, it is critical for the concrete to have a high durability. Chloride penetration could severely reduce the durability of reinforced concrete, resulting in concrete failure. In coastal areas, the concrete has a short service life due to the corrosion of rebars, causing huge economic losses $[2,3]$. The interior of the concrete is highly alkaline. In such an environment, a dense alkaline oxide film will form on the surface of rebars inside the concrete. When acidic substances (e.g. $\mathrm{Cl}^{-}$and $\mathrm{SO}_{4}{ }^{2-}$ ) enter the concrete from the environment, the passive film on the surface of the rebars is damaged, and the rebars will be corroded [4].

Currently, the rebar corrosion in concrete can be prevented by internal measures and external measures. The internal measures mainly refer to the addition of mineral admixtures to the concrete, making the concrete more durable. Mineral admixtures are capable of adsorbing chloride ions. Different mineral admixtures have different consolidation capacities for chloride ions, creating different hydration products. The existing studies have found that the corrosion of rebars can be reduced by adding mineral admixtures (e.g. fly ash, slag, and silica fume) into concrete [5]. The main chemical components of mineral admixtures are $\mathrm{SiO}_{2}$ and $\mathrm{Al}_{2} \mathrm{O}_{3}$. Based on properties, mineral admixtures could be divided into those with hydraulicity, those with pozzolanic effect, and those with both hydraulicity and pozzolanic effect.

The external measures mainly refer to the mixing of rust inhibitors $[6,7]$. The main function of the rust inhibitor is to migrate to the surface of rebars in the form of gas phase or liquid phase, and oxidize the surface into a thick passive film, thereby slowing down or preventing the corrosion of rebars [8] The addition of mineral admixtures or rust inhibitors mainly aims to prevent corrosion of rebars. Many foreign scholars have probed into rust inhibitors. However, rust inhibitors are often applied in a small amount and distributed unevenly in actual applications. Moreover, not much attention has been paid to the interaction between compound rust inhibitor and the matrix.

There are various kinds of rust inhibitors, which inhibit corrosion through complex mechanisms. Based on chemical composition, rust inhibitors fall into three categories, namely, inorganic rust inhibitors, organic rust inhibitors, and compound rust inhibitors. The compound rust inhibitors are usually a mixture of organic and inorganic rust inhibitors. Most of the early rust inhibitors are inorganic, which reduce the compressive strength of concrete. With the advent of organic rust inhibitors (e.g. alcohols and amines), many scholars have found that compound rust inhibitors have better protection effect on rebars [9]. However, there is little report on the effect of compound rust inhibitors on concrete performance.

Taking commonly used slag, fly ash, and silica fume as mineral admixtures, this paper explores how an alcohol-amine compound rust inhibitor affects the compressive strength, chloride penetration resistance, carbonation resistance, and rebar corrosion resistance of concrete with a large amount of mineral admixtures. The research results provide experimental evidence and lay theoretical basis for improving the durability of reinforced concrete. 


\section{MATERIALS AND METHODS}

\subsection{Raw materials}

The raw materials of our tests include P.O. 42.5 cement, Class F fly ash, S95 slag, and silica fume. The specific surface areas (SSA) of these raw materials are $350 \mathrm{~m}^{2} / \mathrm{kg}, 475 \mathrm{~m}^{2} / \mathrm{kg}$, $450 \mathrm{~m}^{2} / \mathrm{kg}$, and $2,100 \mathrm{~m}^{2} / \mathrm{kg}$, respectively. The main chemical components of the cementitious materials are listed in Table 1.

Table 1. The main chemical composition of cementitious materials (mass \%)

\begin{tabular}{ccccc}
\hline Parameters & Cement & Fly ash & Slag & Silica fume \\
\hline $\mathrm{SiO}_{2}$ & 21.66 & 47.69 & 31.56 & 95.01 \\
$\mathrm{Al}_{2} \mathrm{O}_{3}$ & 4.65 & 32.71 & 15.49 & 1.08 \\
$\mathrm{CaO}$ & 61.29 & 9.14 & 39.92 & 0.71 \\
$\mathrm{Fe}_{2} \mathrm{O}_{3}$ & 2.75 & 3.00 & 0.83 & 0.30 \\
$\mathrm{MgO}$ & 2.13 & 0.51 & 6.58 & 0.33 \\
$\mathrm{Na}_{2} \mathrm{O}$ & 1.51 & 1.18 & 1.02 & 0.29 \\
$\mathrm{SO}_{3}$ & 2.29 & 2.84 & 1.79 & 0.17 \\
$\mathrm{LOI}$ & 3.72 & 2.93 & 2.81 & 2.11 \\
\hline
\end{tabular}

The fine aggregate is standard sand with a fineness modulus of 2.7. The coarse aggregate is continuously graded ordinary crushed stone (gravel) of $5 \mathrm{~mm}-20 \mathrm{~mm}$ in particle size. The water-reducing agent is a polycarboxylate-type highefficiency water-reducing agent.

The chemical reagents include $99.5 \%$ sodium chloride (analytically pure), 96\% sodium hydroxide (analytically pure), $12 \%$ hydrochloric acid solution, $98 \% \quad \mathrm{~N}, \quad \mathrm{~N}-$ dimethylethanolamine (DMEA), sodium monofluorophos phate (MFP), and 99.7\% absolute ethanol.

The rebars are 16mm-diameter HRB400 deformed rebars.
The measured yield strength and tensile strength of the rebars are $440 \mathrm{MPa}$ and $560 \mathrm{MPa}$, respectively.

\subsection{Specimen preparation}

As shown in Table 2, a total of 12 groups of specimens were designed, including a control group, aiming to disclose how silica fume content and the DMEA-MFP ratio in the compound rust inhibitor affect the compressive strength, chloride diffusivity, carbonation resistance, and rebar corrosion performance of concrete. To control the slump above $180 \mathrm{~mm}$, the water-binder ratio of the specimens was fixed at 0.32 , and the content of high-efficiency waterreducing agent was kept at $0.1 \%$.

The specimens were prepared in the following steps: Mix cement, fly ash, slag, silica fume, sand, and gravel in a horizontal concrete mixer for $3 \mathrm{~min}$ mixing. Blend water, compound rust inhibitor, and water reducer evenly, and pour the mixture into the mixer for $5 \mathrm{~min}$ stirring. Quickly pour the fresh mixture into concrete molds of different sizes, and place each mold on a shaking table for 60 s vibration. Cover the surface of each mold with plastic wrap, and relocate the mold into a standard curing room for $1 \mathrm{~d}$ curing at relative humidity (RH) of $95 \pm 1 \%$ and temperature (T) of $20 \pm 2{ }^{\circ} \mathrm{C}$. After that, demold the specimens, and cure them to the test age.

The concrete molds include $100 \mathrm{~mm} \times 100 \mathrm{~mm} \times 100 \mathrm{~mm}$ triple molds, $\quad 100 \mathrm{~mm} \times 100 \mathrm{~mm} \times 400 \mathrm{~mm}$ triple molds, $500 \mathrm{~mm} \times 150 \times 46 \mathrm{~mm}$ triple molds, and $\Phi 100 \mathrm{~mm} \times 200 \mathrm{~mm}$ cylindrical molds.

In the accelerated corrosion test on rebars, the rebar length was fixed at $450 \mathrm{~mm}$. At the end of each rebar, a standard threaded hole (diameter: $5 \mathrm{~mm}$ ) was embedded to weld the rebar to the electrical wire.

Table 2. The mix ratio of concrete $\left(\mathrm{kg} / \mathrm{m}^{3}\right)$

\begin{tabular}{cccccccccc}
\hline No. & C & FA & S & SF & DMEA & MFP & Sand & Gravel & Water \\
\hline Control & 224 & 168 & 168 & 0 & 0 & 0 & 565 & 1050 \\
D-M0 & 224 & 168 & 168 & 0 & 1.8 & 0 & 565 & 1050 & 168 \\
D20-M & 224 & 168 & 168 & 0 & 1.8 & 0.09 & 565 & 1050 \\
D15-M & 224 & 168 & 168 & 0 & 1.8 & 0.12 & 565 & 1050 & 168 \\
D10-M & 224 & 168 & 168 & 0 & 1.8 & 1.8 & 565 & 1050 & 168 \\
D5-M & 224 & 168 & 168 & 0 & 1.8 & 0.36 & 565 & 1050 & 168 \\
FA-SF5 & 224 & 140 & 168 & 28 & 1.8 & 0.12 & 565 & 1050 \\
FA-SF10 & 224 & 112 & 168 & 56 & 1.8 & 0.12 & 565 & 1050 \\
FA-SF15 & 224 & 84 & 168 & 84 & 1.8 & 0.12 & 565 & 1050 \\
S-SF5 & 224 & 168 & 140 & 28 & 1.8 & 0.12 & 565 & 1050 \\
S-SF10 & 224 & 168 & 112 & 56 & 1.8 & 0.12 & 565 & 1058 \\
S-SF15 & 224 & 168 & 84 & 84 & 1.8 & 0.12 & 565 & 1058 \\
\hline
\end{tabular}

Note: $\mathrm{C}$ is cement; FA is fly ash; $\mathrm{S}$ is slag; $\mathrm{SF}$ is silica fume.

\subsection{Test methods}

This paper tests the compressive strength, chloride diffusivity, and the accelerated rebar corrosion in concrete mixed with compound rust inhibitor.

(1) Compressive strength test:

The compressive strength of concrete was tested according to Standard for Test Method of Mechanical Properties on Ordinary Concrete (GB/T50081-2016). The 28d and 90d compressive strengths of three specimens in each test group. The mean value of the three specimens was taken as the compressive strength of that test group [10].

(2) Chloride diffusivity test:

The chloride diffusivity was tested by rapid chloride migration $(\mathrm{RCM})$. The $\Phi 100 \mathrm{~mm} \times 50 \mathrm{~mm}$ cylindrical specimens were selected $7 \mathrm{~d}$ before the test, and cut into three $\Phi 100 \mathrm{~mm} \times 50 \mathrm{~mm}$ small cylindrical specimens. The test was conducted according to Standard for Test Methods of LongTerm Performance and Durability of Ordinary Concrete (GB/T 50082-2009). During the test, the chloride diffusivities of three specimens in each test group were measured, and the mean value was taken as the chloride diffusivity of that group. For each specimen, the chloride diffusivity can be calculated by:

$$
D_{R C M}=\frac{0.0239 \times(273+\mathrm{T}) \mathrm{L}}{(\mathrm{U}-2) \mathrm{t}}\left(\mathrm{X}_{\mathrm{d}}-0.0238 \sqrt{\frac{(273+\mathrm{T}) \mathrm{LX}}{\mathrm{U}-2}}\right)
$$


where, $\mathrm{U}$ is the absolute voltage $(\mathrm{V})$; $\mathrm{T}$ is the mean of the initial temperature and the end temperature of the anode solution $\left({ }^{\circ} \mathrm{C}\right)$; $\mathrm{L}$ is the thickness of the specimen $(\mathrm{mm}) ; X_{d}$ is the mean depth of chloride penetration (ten penetration depths were measured at equal distances using a micrometer, and the mean value was taken with an accuracy of $0.1 \mathrm{~mm}$ ); $\mathrm{t}$ is the test duration (h).

(3) Carbonation resistance test:

The carbonation resistance was tested according to $\mathrm{GB} / \mathrm{T}$ $50082-2009$, using $100 \mathrm{~mm} \times 100 \mathrm{~mm} \times 100 \mathrm{~mm}$ prism specimens. Before the test, the specimens were vacuum dried for $48 \mathrm{~h}$. Parallel lines were drawn longitudinally every $10 \mathrm{~mm}$ on both sides of each specimen, and epoxy resin was applied to the four sides of the specimen. The test was performed in a carbonation box with a $\mathrm{CO}_{2}$ content of $20 \%$. The carbonation depth of each specimen was measured on the $3^{\text {rd }}, 7^{\text {th }}, 14^{\text {th }}, 28^{\text {th }}$, and $60^{\text {th }}$ day. After reaching each test age, the specimens were cut open, and applied with phenolphthalein solution to measure the carbonation depth.

(4) Accelerated rebar corrosion test:

At present, there are many domestic methods for testing the rust resistance of admixtures or mineral admixtures, including industry standards or specifications like Technical Specification for Application of Corrosion Inhibitor for Steel Bar, Standard for Test Methods of Long-Term Performance and Durability of Ordinary Concrete, and Concrete Admixtures. However, there is not yet a complete set of methods that can systematically measure rust resistance. Among the available methods, the electrical accelerated test is the easiest and most accurate way to test rust resistance.

Rebars are corroded rather slowly in natural environment. In this test, the rebar corrosion was accelerated using electric wires to connect each rebar with the positive pole of the power supply, and arranging the wires in parallel connection. Three rebars were tested for each group, that is, a total of 36 rebars were tested. The specimens of every six test groups are connected in parallel with a direct current (DC) power supply. The energization lasted for $30 \mathrm{~d}$. Then, the concrete specimens were crushed; the rebars were taken out, cleaned with acid, dried, and weighed. The rebar corrosion rate $\mathrm{L}_{0}$ can be calculated by:

$$
\mathrm{L}_{0}=\frac{w-w_{0}}{w} \times 100
$$

where, $\mathrm{w}_{\text {and }} \mathrm{w}_{0}$ are the mass of the rebar before corrosion and after corrosion and acid pickling, respectively $(\mathrm{g})$.

\section{TEST RESULTS AND ANALYSIS}

\subsection{Compressive strength}

Compressive strength is the most intuitive evaluation index of concrete performance [11]. The results of compressive strength test are displayed in Figure 1.

As shown in Figure 1(a), at the curing age of $28 \mathrm{~d}$, the addition of rust inhibitor suppressed the compressive strength of concrete. At the curing age of $90 \mathrm{~d}$, the highest compressive strength belonged to the concrete mixed with DMEA rust inhibitor; the mixing of MFP reduced the compressive strength of concrete; the greater the MFP content, the smaller the compressive strength.

The main reason is that the addition of rust inhibitor hinders the early hydration of cementitious materials in concrete, resulting in a decline in the $28 \mathrm{~d}$ compressive strength. With the growth of curing age, a large amount of fly ash and slag undergo secondary hydration reactions with the products of cement hydration $[12,13]$. As a result, the $90 \mathrm{~d}$ compressive strength of test specimens was similar to that of control specimens. However, the MFP significantly reduced the compressive strength of concrete $[14,15]$.

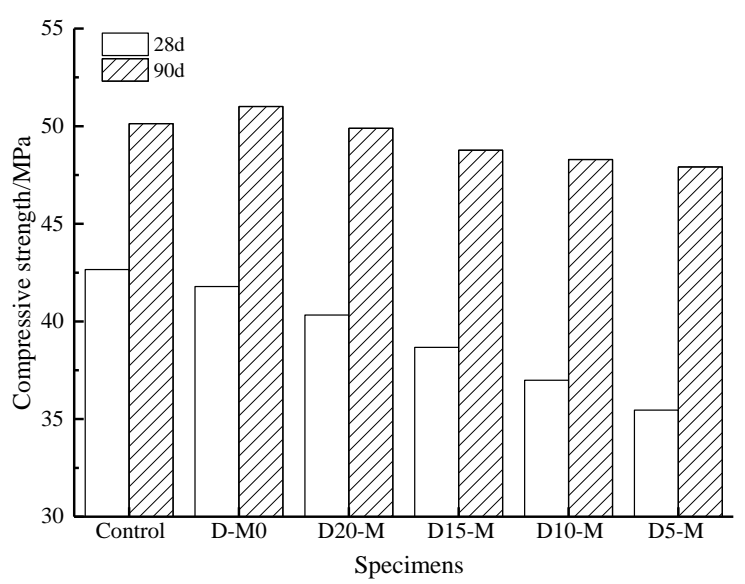

(a) Compound rust inhibitor

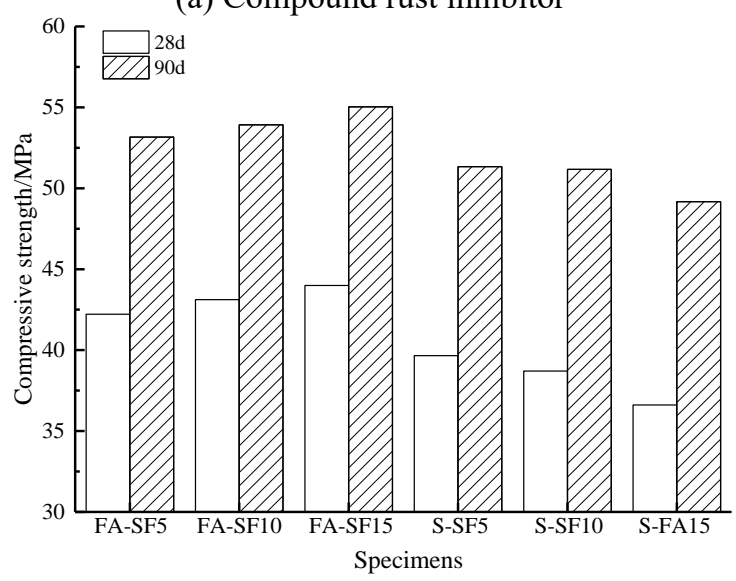

(b) Silica fume content

Figure 1. The compressive strength of concrete

As shown in Figure 1(b), the compressive strength of concrete obviously increased, as fly ash was replaced with silica fume. The main reason is that the large SSA of silica fume provides a large amount of $\mathrm{SiO}_{2}$ for secondary hydration, which improves the pore structure and enhances the density of concrete. Besides, the compressive strength decreased, as slag was replaced with silica fume. Overall, the increment or decrement was not remarkable, falling between $2 \%$ and $5 \%$.

Furthermore, it can be clearly seen that the replacement of slag with silica fume reduced the $28 \mathrm{~d}$ compressive strength, and $90 \mathrm{~d}$ compressive strength. The reduction of compressive strength results from the properties of different materials: Slag is a highly active cementitious material with both hydraulicity and pozzolanic effect, and tend to participate in the early hydration of cement. By contrast, fly ash only contains lots of active $\mathrm{SiO}_{2}$ and $\mathrm{Al}_{2} \mathrm{O}_{3}$, which cannot take part in cement hydration unless the environment is strongly alkaline. Hence, it is better to make silica fume a replacement of fly ash than a replacement of slag.

\subsection{Chloride penetration resistance}

Fly ash, slag, and silica fume, as mineral admixtures, facilitate the cementation of concrete. In steady-state chloride 
ion test, these auxiliary cementitious materials have strong binding capacity of chloride ions [16-18]. In our research, the chloride diffusivity is tested by the RCM method, which has nothing to do with the binding capacity of chloride ions. The main aim is to test the diffusion rate of chloride ions in concrete. Table 3 lists the results of chloride diffusivity test.

Comparing the control specimen with the specimens mixed with compound rust inhibitor, it can be found that the chloride diffusivity was clearly reduced by the addition of the rust inhibitor. The chloride diffusivity of D-M0, D20-M, D15-M, D10-M, and D5-M was $19.47 \%, 37.85 \%, 34.43 \%, 30.84 \%$, and $22.42 \%$ lower than that of control specimen, respectively.

Moreover, it is obvious that the chloride diffusivity of concrete was minimized at the DMEA-MFP ratio of 15:1. With the increase of MFP content, the chloride diffusivities of test specimens rose across the board, but all below the chloride diffusivity of the control specimen [19].

Furthermore, adding silica fume could reduce the chloride diffusivity of concrete [20, 21]. Compared with D20-M, the specimens mixed with silica fume all had low chloride diffusivities. Besides, as the silica fume content grew, the chloride diffusivities of all specimens exhibited a decline. This is mainly attributable to the large SSA of silica fume. Inside the concrete, silica fume not only provides the $\mathrm{SiO}_{2}$ required for reactions, but also filled up the gaps, making the concrete more compact.

Table 3. The chloride diffusivity of concrete $\left(10^{-12} \mathrm{~m}^{2} / \mathrm{s}\right)$

\begin{tabular}{cccc}
\hline Specimen & $\begin{array}{c}\text { Chloride } \\
\text { diffusivity }\end{array}$ & Specimen & $\begin{array}{c}\text { Chloride } \\
\text { diffusivity }\end{array}$ \\
\hline Control & 6.42 & FA-SF5 & 3.74 \\
D-M0 & 5.17 & FA-SF10 & 3.51 \\
D20-M & 4.21 & FA-SF15 & 3.09 \\
D15-M & 3.99 & S-SF5 & 3.87 \\
D10-M & 4.44 & S-SF10 & 3.78 \\
D5-M & 4.98 & S-SF15 & 3.73 \\
\hline
\end{tabular}

\subsection{Carbonation resistance}

Inside hardened concrete, the rebars are protected by the alkaline environment. In the natural environment, however, the alkaline substance $\mathrm{Ca}(\mathrm{OH})_{2}$ in the concrete react with $\mathrm{CO}_{2}$, reducing the $\mathrm{pH}$ within the concrete $[22,23]$. Then, the alkaline protection will cease to exist, causing rebar corrosion. The concrete carbonation is mainly affected by material factors and environmental factors. The addition of mineral admixtures and compound rust inhibitor will directly change the hydration components in the concrete. The results of carbonation resistance test are presented in Figure 2.

As shown in Figure 2(a), with the increase of carbonation age, the carbonation depth of concrete exhibited an increasing trend, but the increment was gradually falling. Compared with the control specimen, the compound rust inhibitor effectively reduced the penetration depth of $\mathrm{CO}_{2}$, indicating that the inhibitor enhances the carbonation durability of concrete.

Also, the carbonization depth of concrete was minimized at the DMEA-MFP ratio of 15:1. Similar to the trend of chloride diffusivity, with the increase of MFP content, the carbonation depths of test specimens rose across the board, but all below carbonation depth of the control specimen.

As shown in Figure 2(b), the addition of silica fume promoted the carbonation resistance of concrete, but to a very limited extent.

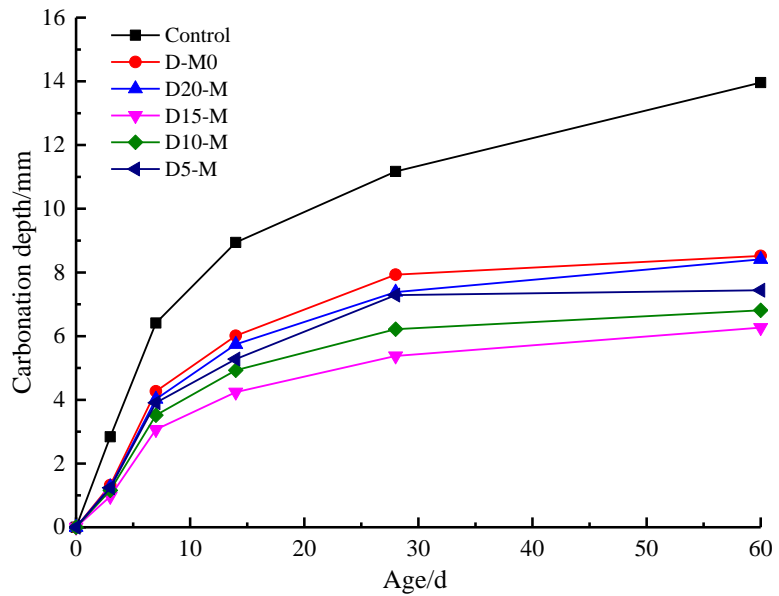

(a) Compound rust inhibitor

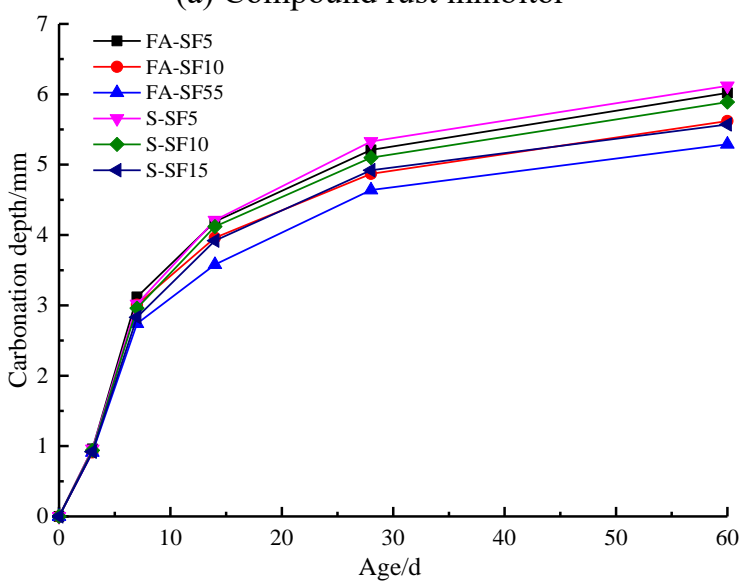

(b) silica fume content

Figure 2. The carbonation depth of concrete

\subsection{Rebar corrosion resistance}

The variation of internal admixtures will change the chemical composition of concrete, which in turn alters the resistivity of the concrete [24]. During the rebar corrosion resistance test, the rebars were connected in parallel, so that every group of rebars has the same corrosion voltage. Thus, the corrosion resistance of each rebar directly depends on the resistivity of the rebar and the surrounding concrete. With the elapse of energization time, the corrosion products will accumulate, reducing the corrosion growth rate. In this test, every group of rebars was energized for $30 \mathrm{~d}$.

Table 4 shows the test results on the corrosion rate of the rebars. Compared with the control specimen, the addition of rust inhibitor significantly reduced the corrosion loss of the rebars in the concrete. The lowest corrosion rate was observed at the DMEA-MFP ratio of 15:1. The mixing of silica fume only slightly enhanced the corrosion resistance of rebars in concrete.

Table 4. The corrosion rate of rebar (\%)

\begin{tabular}{cccc}
\hline Specimen & $\begin{array}{c}\text { Corrosion } \\
\text { rate/\% }\end{array}$ & Specimen & $\begin{array}{c}\text { Corrosion } \\
\text { rate/\% }\end{array}$ \\
\hline Control & 13.72 & FA-SF5 & 3.71 \\
D-M0 & 5.74 & FA-SF10 & 3.64 \\
D20-M & 4.26 & FA-SF15 & 3.71 \\
D15-M & 3.96 & S-SF5 & 4.03 \\
D10-M & 4.47 & S-SF10 & 3.82 \\
D5-M & 4.91 & S-SF15 & 3.77 \\
\hline
\end{tabular}


Figure 3 provides the $30 \mathrm{~d}$ cumulative power of the specimens mixed with the compound rust inhibitor. It can be seen that the $30 \mathrm{~d}$ cumulative power is positively correlated with the corrosion rate of the rebar. As above, single factor analysis also shows that a large amount of mineral admixtures and the rust inhibitor promoted each other in the suppressing of chloride penetration. The interaction between compound rust inhibitor and mineral admixtures creates a dense gel layer of hydration products, which reduces the infiltration capacity of chloride ions.

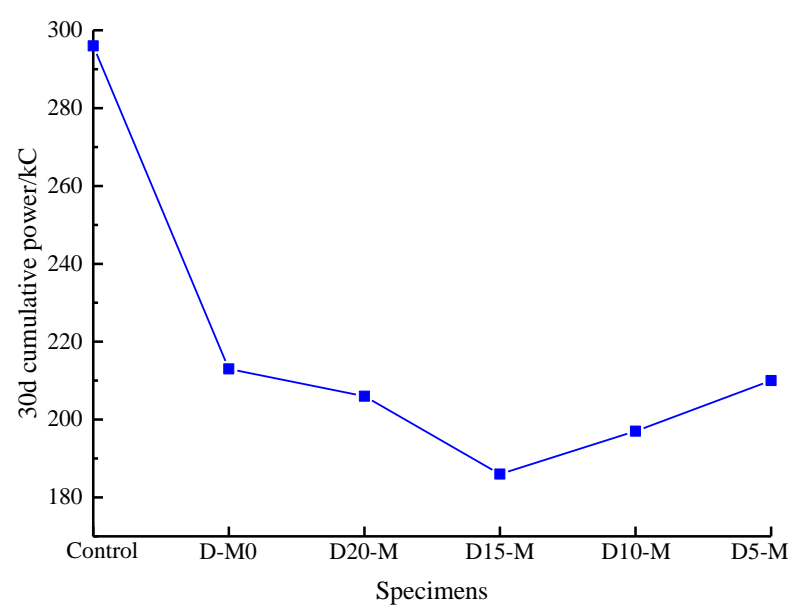

Figure 3. The $30 \mathrm{~d}$ cumulative power of concrete

\section{CONCLUSIONS}

This paper studies how the contents of compound rust inhibitor and silica fume affect the compressive strength, chloride diffusivity, carbonation resistance, and corrosion resistance of the concrete with a large amount of mineral admixtures. The main conclusions are as follows:

(1) The addition of rust inhibitor hinders the early hydration of cementitious materials in concrete, resulting in a decline in the $28 \mathrm{~d}$ compressive strength. In the long run, the addition of rust inhibitor does not have a significant impact on the compressive strength of concrete. The compressive strength of concrete could be increased by replacing fly ash with silica fume, and decreased by replacing slag with silica fume.

(2) The chloride diffusivity and carbonation depth of concrete were minimized at the DEMA-MFP ratio of 15:1. The composite rust inhibitor makes the concrete more resistant to chloride penetration and carbonation. Besides, the addition of rust inhibitor clearly suppressed the corrosion loss of the rebars in concrete.

(3) The addition of silica fume improves the strength and durability of concrete, and slightly enhances the resistance to rebar corrosion, carbonation, and chloride penetration.

\section{REFERENCES}

[1] Pan, Z.H., Hiromi, F., Wee, T.H. (2007). Preparation of high performance foamed concrete from cement, sand and mineral admixtures. Journal of Wuhan University of Technology Materials Science Edition, 22(2): 295-298. https://doi.org/10.1007/s11595-005-2295-4

[2] Xu, C., Jin, W.L., Wang, H.L., Wu, H.T., Huang, N., Li, Z.Y., Mao, J.H. (2016). Organic corrosion inhibitor of triethylenetetramine into chloride contamination concrete by Eletro-injection method. Construction \& Building Materials, 115: 602-617. https://doi.org/10.1016/j.conbuildmat.2016.04.076

[3] Pokhurs kyi, V.I., Marukha, V.I., Zin, I., Hnyp, I.P., Bilyi, L.M. (2011). Inhibitor protection of the steel reinforcement of armored concrete damaged by cracks. Materials $\quad$ Science, 46(5): 573-582. https://doi.org/10.1007/s11003-011-9326-4

[4] Yang, E.I., Ryu, J.H., Youm, K.S., Hwang, I.D., Kim, M.Y. (2008). Mechanical characteristics and corrosion resistance of concrete using tannin acid-corrosion inhibitor. Journal of the Korea Concrete Institute, 20(6): 741-746. https://doi.org/10.4334/JKCI.2008.20.6.741

[5] Génin, J.M.R., Dhouibi, L., Refait, P., Abdelmoula, M., Triki, E. (2002). Influence of phosphate on corrosion products of iron in chloride-polluted-concrete-simulating solutions: ferrihydrite vs green rust. Corrosion, 58(6): 467-478. https://doi.org/10.5006/1.3277637

[6] Huang, Z.D. (2013). Study on high amount mineral admixtures concrete performance. Applied Mechanics \& Materials, 357-360: 667-670. https://doi.org/10.4028/www.scientific.net/AMM.357360.667

[7] Sun, C.T., Chen, M.S., Zheng, H.B., Zhang, P., Li, Y.T., Hou, B.R. (2019). The effect of amino-alcohol-based corrosion inhibitors on concrete durability. Canadian Journal of Civil Engineering, 58(6): 467-478. https://doi.org/10.1139/cjce-2018-0482

[8] Gu, C., Wang, Y., Gao, F., Yang Y., Ni, T., Liu, J., Lou, X., Chen, J. (2019). Early age tensile creep of high performance concrete containing mineral admixtures: experiments and modeling. Construction and Building Materials, $\quad$ 197(10): 766-777. https://doi.org/10.1016/j.conbuildmat.2018.11.218

[9] Le, H.T., Ludwig, H.M. (2015). Effect of rice husk ash and other mineral admixtures on properties of selfcompacting high performance concrete. Materials and Design, $\quad 89$ : 156-166. https://doi.org/10.1016/j.matdes.2015.09.120

[10] Le, H.T., Müller, M., Siewert, K., Ludwig, H.M. (2015). The mix design for self-compacting high performance concrete containing various mineral admixtures. Materials \& design, 72(5): 51-62. https://doi.org/10.1016/j.matdes.2015.01.006

[11] Liu, J.Z., Geng, J.D., Wang, H., Ba, M.F., He, Z.M. (2019). Influence of nitrite on chemical composition of passivation film of steel bars under the coupling effects of carbonization and chloride. Anti Corrosion Methods \& Materials, 66(2): 230-235. https://doi.org/10.1108/ACMM-09-2018-1999

[12] Chen, C.C., Cai, J.S., Liu, J.Z., Liu, J.P. (2015). Use of aminoalcohol as inhibitor in chloride-contaminated steel reinforced concrete. Journal of the Chinese Ceramic Society, 43(4): 393-399. https://doi.org/10.14062/j.issn.0454-5648.2015.04.05

[13] Qiao, G.F., Hong, Y., Liu, T.J., Ou, J.P. (2013). Passive corrosion control and active corrosion prevention of the reinforced concrete structures by electrochemical chloride removal and inhibitors. Anti Corrosion Methods $\begin{array}{lll}\text { \& } & \text { Materials, } & \text { 32-37. }\end{array}$ https://doi.org/10.1108/ACMM-03-2012-1156

[14] Cai, J., Chen, C., Liu, J., Liu, J. (2014). Corrosion resistance of carbon steel in simulated concrete pore 
solution in presence of 1-dihydroxyethylamino-3dipropylamino-2-propanol as corrosion inhibitor. British Corrosion Journal, 49(1): 66-72. https://doi.org/10.1179/1743278213Y.0000000109

[15] Ormellese, M., Bolzoni, F., Goidanich, S., Pedeferri, M., Brenna, A. (2011). Corrosion inhibitors in reinforced concrete structures part 3-Migration of inhibitors into concrete. Corrosion Engineering Science \& Technology, 46(4): 334-339. https://doi.org/10.1179/174327809X419230

[16] Fei, F.L., Hu, J., Yu, Q.J., Wei, J.X., Nong, Y.B. (2015). The effect of a tailored electro-migrating corrosion inhibitor on the corrosion performance of chloridecontaminated reinforced concrete. Materials and Corrosion, 66(10): 1039-1050. https://doi.org/10.1002/maco.201508231

[17] Blankson, M.A., Erdem, S. (2015). Comparison of the effect of organic and inorganic corrosion inhibitors on the rheology of self-compacting concrete. Construction and Building Materials, 77(feb.15): 59-65. https://doi.org/10.1016/j.conbuildmat.2014.12.032

[18] Lee, H.S., Yang, H.M., Singh, J.K., Prasad, S.K., Yoo, B. (2018). Corrosion mitigation of steel rebars in chloride contaminated concrete pore solution using inhibitor: an electrochemical investigation. Construction and Building Materials, 173(JUN.10): 443-451. https://doi.org/10.1016/j.conbuildmat.2018.04.069

[19] Volpi, E., Foiadelli, C., Trasatti, S., Koleva, D.A. (2017). Development of smart corrosion inhibitors for reinforced concrete structures exposed to a microbial environment.
Industrial \& Engineering Chemistry Research, 56(20): 5778-5794. https://doi.org/10.1021/acs.iecr.7b00127

[20] Anitha, R., Chitra, S., Hemapriya, V., Chung, I.M., Kim, S.H., Prabakaran, M. (2019). Implications of ecoaddition inhibitor to mitigate corrosion in reinforced steel embedded in concrete. Construction and Building Materials, 213: 246-256. https://doi.org/10.1016/j.conbuildmat.2019.04.046

[21] Asaad, M.A., Ismail, M., Tahir, M.M., Huseien, G.F., Raja, P.B., Asmara, Y.P. (2018). Enhanced corrosion resistance of reinforced concrete: role of emerging ecofriendly elaeis guineensis/silver nanoparticles inhibitor. Construction and Building Materials, 188(NOV.10): 555-568. https://doi.org/10.1016/j.conbuildmat.2018.08.140

[22] Fazayel, A.S., Khorasani, M., Sarabi, A.A. (2018). The effect of functionalized polycarboxylate structures as corrosion inhibitors in a simulated concrete pore solution. Applied Surface Science, 441(MAY31): 895-913. https://doi.org/10.1016/j.apsusc.2018.02.012

[23] Balonis, M., Sant, G., Lsgor, O.B. (2018). Mitigating steel corrosion in reinforced concrete using functional coatings, corrosion inhibitors, and atomistic simulations. Cement \& Concrete Composites, 101: 15-23. https://doi.org/ 10.1016/j.cemconcomp.2018.08.006

[24] Bolzoni, F., Goidanich, S., Lazzari, L., Ormellese, M. (2006). Corrosion inhibitors in reinforced concrete structures part 2 - repair system. Corrosion Engineering Science and Technology, 41(3): 212-220. https://doi.org/10.1179/174327806X111234 